Susannah K. Leaver

Niall S. MacCallum

Vasisht Pingle

Matthew B. Hacking

Gregory J. Quinlan

Timothy W. Evans

Anne Burke-Gaffney

\section{Increased plasma thioredoxin levels in patients with sepsis: positive association with macrophage migration inhibitory factor}

Received: 2 March 2009

Accepted: 12 August 2009

Published online: 15 September 2009

(C) The Author(s) 2009. This article is published with open access at Springerlink.com
S. K. Leaver - N. S. MacCallum •

G. J. Quinlan · T. W. Evans .

A. Burke-Gaffney (ه)

Unit of Critical Care, Respiratory Science,

National Heart and Lung Institute Division,

Faculty of Medicine, Imperial College

London, London SW3-6LY, UK

e-mail: a.burke-gaffney@imperial.ac.uk

Tel.: +44-20-73518217

Fax: +44-20-7351-8524

V. Pingle $\cdot$ T. W. Evans

Adult Intensive Care Unit,

Royal Brompton Hospital,

London SW3-6NP, UK

M. B. Hacking

Department of Critical Care,

Royal Marsden Hospital,

London SW3 6JJ, UK
Abstract Purpose: To establish the relationship between plasma levels of thioredoxin (Trx) and macrophage migration inhibitory factor (MIF) in systemic inflammatory stress syndrome (SIRS)/sepsis. Methods: Enzyme-linked immunosorbent assay measurements of Trx, MIF, IL-6, -8, and -10 and enzymelinked fluorescent assay determination of procalcitonin (PCT) in plasma from patients with SIRS/sepsis, neutropenic sepsis, healthy volunteers and pre-oesophagectomy patients. Results: Thioredoxin was significantly higher in SIRS/sepsis patients [101.3 $\mathrm{ng} \mathrm{ml}^{-1}$, interquartile range (IQR) 68.7-155.6, $n=32]$ compared with that in healthy controls (49.5 $\mathrm{ng} \mathrm{ml}^{-1}$, IQR 31.4-71.1, $P<0.001, n=17)$ or pre-oesophagectomy patients $\left(40.5 \mathrm{ng} \mathrm{ml}^{-1}\right.$, IQR 36.9-63.2, $P<0.01, n=7$ ), but was not raised in neutropenics $(n=5)$. MIF levels were also significantly higher in SIRS/sepsis patients (12.1 $\mathrm{ng} \mathrm{ml}^{-1}$, IQR 9.5-15.5, $n=35$ ), but not in the neutropenic group, when compared with healthy controls (9.3 $\mathrm{ng} \mathrm{ml}^{-1}$, IQR 7.3-10.7, $P<0.01, n=20)$. Trx levels correlated, positively, with MIF levels and APACHE II scores. Plasma levels of IL-6, -8 and -10 and PCT increased significantly in patients with SIRS/sepsis $(P<0.001)$ and with neutropenic sepsis, but did not correlate with Trx or MIF levels. Conclusion: Plasma levels of Trx, MIF, IL-6, -8, -10 and PCT were raised in patients with SIRS/sepsis. Comparisons between mediators suggest a unique correlation of Trx with MIF. Moreover, Trx and MIF differed from cytokines and PCT in that levels were significantly lower in patients with neutropenia compared with the main SIRS/sepsis group. By contrast, IL-8 and PCT levels were significantly greater in the neutropenic patient group. The link between MIF and Trx highlighted in this study has implications for future investigations into the pathogenesis of SIRS/ sepsis.

Keywords Sepsis - Systemic inflammatory response syndrome . Thioredoxin - Macrophage inflammatory factor - Cytokines . Procalcitonin

\section{Introduction}

Sepsis and its sequelae are the leading causes of death amongst the critically ill in non-coronary intensive care units. Currently, treatment for sepsis is largely supportive, based upon fluid resuscitation and administration of vasopressors and antibiotics. The only pharmacotherapy shown to reduce mortality in sepsis, in a randomised clinical trial, is activated protein $C$ [1]. A greater understanding of the pathophysiology of sepsis/systemic 
inflammatory stress syndrome (SIRS) could help identify other effective pharmacotherapies. One therapy that has shown promise in an animal model of sepsis is an antimacrophage migration inhibitory factor (MIF) antibody [2]. MIF is a $12 \mathrm{kDa}$, pro-inflammatory protein, released from immune cells and levels are raised in sepsis [3-5]. Identification of a redox motif in MIF similar to that in thioredoxin (Trx) has led to the re-classification of MIF as a Trx-like protein $[6,7]$.

Thioredoxin is a ubiquitous, $12.5 \mathrm{kDa}$ intracellular thiol protein with a redox active site containing a conserved Cys-Gly-Pro-Cys which facilitates protein reduction [8]. Trx is a potent anti-oxidant that modulates inflammation, cell growth and apoptosis [8]. Released during inflammation and oxidative stress, Trx is elevated in many medical/surgical conditions [8]. There are conflicting reports of plasma Trx levels in sepsis. Specifically, we have shown decreased plasma Trx in children with meningococcal septic shock (MSS), [9] whilst others demonstrated increased plasma Trx in adults with severe sepsis [10]. A positive correlation between serum Trx and MIF levels in inflammatory bowel diseases (IBD) has been shown [11]. In experimental models of IBD Trx was anti-inflammatory, suppressing MIF release/ activity [11].

The aim of this study was twofold. First, to determine plasma levels of Trx and MIF in adult patients during the acute phase of SIRS/sepsis compared with healthy controls, pre-oesophagectomy patients and a small sub-group of patients with neutropenic sepsis. Second, to establish whether plasma levels of Trx and MIF correlate with each other; or with IL-8, -10 or -6 , cytokines implicated in the pathophysiology of sepsis; with procalcitonin (PCT), a marker of bacterial infectious disease [12] or finally, indices of disease severity and organ failure.

\section{Materials and methods}

Plasma samples were collected from 35 patients with confirmed sepsis, or SIRS with a high clinical suspicion of sepsis, admitted from March 2005 to June 2007 to either the adult intensive care unit (AICU) of the Royal Brompton Hospital (RBH; $n=32$ ) or the AICU of the Royal Marsden Hospital (RHM; $n=3$ ). Patients met the American College of Chest Physicians/Society of Critical Care Medicine (ACCP/SCCM) consensus conference definition for severe sepsis [13]. A small group of patients with neutropenic sepsis were also recruited from RMH $(n=4)$ and $\mathrm{RBH}(n=1)$. All patients were intubated and mechanically ventilated. Two control groups were also recruited; healthy volunteers $(n=20 ; 10$ men, 10 women) and patients requiring oesophagectomy for carcinoma from the RMH ( $n=8 ; 6$ men, 2 women). The latter group was chosen in order to determine whether hospital admission and intubation affect Trx and MIF levels. Approval for collection and analyses of samples was obtained from the local research ethics committee. Informed, written consent was obtained from control patients and assent from relatives for patients with SIRS/ sepsis and neutropenic sepsis.

Blood samples were collected from patients via an indwelling arterial cannula and from healthy controls via antecubital venepuncture. Blood from septic patients was collected into lithium heparin tubes within $24 \mathrm{~h}$ of onset of illness meeting criteria for SIRS/sepsis and from oesophagectomy patients directly after intubation, $30 \mathrm{~min}$ prior to oesophagectomy. Plasma was separated (1300 $g$, $4^{\circ} \mathrm{C}, 6 \mathrm{~min}$ ) and stored at $-80^{\circ} \mathrm{C}$. We have shown previously that Trx levels are stable in stored plasma samples [14].

Disease severity and organ failure were assessed using Acute Physiology and Chronic Health Evaluation (APACHE) II scores and Sequential Organ Failure Assessment (SOFA) scores and calculated using the worst physiological and biochemical parameters recorded during the $24 \mathrm{~h}$ period following study admission. Amongst intensive care scoring systems, APACHE II scores are favoured, because of ease of use and inclusion in the calculation of age, co-morbidity, and other physiological variables, indeed significantly more than other scoring systems.

Procalcitonin was measured by enzyme-linked fluorescent assay (Vidas Brahms, bioMérieux Marcy l'Etoile, France) and analysed on a Biomerieux Vidas analyser. Commercially available sandwich enzymelinked immunosorbent assay (ELISA) kits were used to measure IL-6, -8 (Hycult, Uden, Netherlands), IL-10 (BD Biosciences, Erembodegem, Belgium) MIF (R \& D Systems, Abingdon, UK) and Trx (Redox Biosciences, Kyoto, Japan) in duplicate samples. As erythrocytes have high Trx levels relative to the amounts found in plasma, free haemoglobin was measured with a HemoCue plasma/Low $\mathrm{Hb}$ photometer and Trx concentrations corrected for release from haemolysed erythrocytes, as described, previously, by us and others [14, 15]. Highly haemolysed blood samples $(\mathrm{Hb}>65 \mathrm{mg} / \mathrm{dl})$, from three healthy volunteers, three sepsis/SIRS patients and one pre-oesophagectomy patient, were excluded from Trx, but not other, measurements.

Data were expressed as median values and interquartile ranges (IQR) and analysed using non-parametric analysis. Comparisons between groups were made using a two-tailed Mann-Whitney $U$ or Kruskal-Wallis tests and correlations between variables were assessed using Spearman analysis. To assess effects of age as a controlling variable on correlations between MIF and Trx data were log transformed, subjected to partial correlation analysis, Pearson correlation coefficients calculated with and without age and values compared. $P$ values of $<0.05$ were considered significant. 


\section{Results}

Patients with SIRS/sepsis (severe sepsis, $n=3$; septic shock, $n=32$ ) and those with neutropenic sepsis fulfilling the criteria for septic shock $(n=5)$ were recruited. There was no significant difference in age between patient groups (Table 1) and the hospitalised control group [66.3 years (IQR 58-74.7)]. However, the age of the healthy control group [32.5 years (IQR 28.5-34)] was significantly less $(P<0.0001)$ than that of the patient groups. Detailed demographic, clinical and microbiological information for SIRS/sepsis patients are presented in Table 1.

Table 1 Characteristics of patients with SIRS/sepsis and neutropenic sepsis

\begin{tabular}{|c|c|c|}
\hline & SIRS/sepsis & $\begin{array}{l}\text { Neutropenic } \\
\text { sepsis }\end{array}$ \\
\hline Age $(\text { years })^{\mathrm{a}}$ & $64.4(46.8-75)$ & $60.8(57.6-61.5)$ \\
\hline Gender $\mathrm{M} / \mathrm{F}$ & $22 / 13$ & $2 / 3$ \\
\hline APACHE II score ${ }^{a}$ & $19(15-23)$ & $23.4(20.5-26.5)$ \\
\hline SOFA $^{\mathrm{a}}$ & $9(8-10)$ & $12(9-12.5)$ \\
\hline Survival to hospital discharge & $25(71.4 \%)$ & $3(60 \%)$ \\
\hline \multicolumn{3}{|c|}{ Primary cause of admission } \\
\hline Medical & 12 & 5 \\
\hline Cardiac & 5 & 0 \\
\hline Respiratory & 5 & 4 \\
\hline Other & 2 & 1 \\
\hline Surgical & 23 & 0 \\
\hline Cardiac & 16 & - \\
\hline Thoracic & 5 & - \\
\hline Other & 2 & - \\
\hline Sepsis on admission & 13 & 3 \\
\hline \multicolumn{3}{|l|}{ Co morbidities } \\
\hline Chronic pulmonary disease & $17 \%$ & $40 \%$ \\
\hline Ischaemic heart disease & $46 \%$ & - \\
\hline Diabetes & $23 \%$ & - \\
\hline Neoplasm & $23 \%$ & $100 \%$ \\
\hline Renal, liver, other & $17 \%$ & $80 \%$ \\
\hline Body temperature $\left({ }^{\circ} \mathrm{C}\right)^{\mathrm{a}}$ & $\begin{array}{l}37.5(36.8- \\
38.5)\end{array}$ & $38(37.3-38.7)$ \\
\hline $\begin{array}{l}\text { Total leukocyte count } \\
\qquad\left(\times 10^{9}\right)^{\mathrm{a}}\end{array}$ & $13.6(11-17.8)$ & $0.1(0.1-1.6)$ \\
\hline Neutrophils $\left(\times 10^{9}\right)^{\mathrm{a}}$ & $10.8(11-17.8)$ & $0(0-1.6)$ \\
\hline Monocytes $\left(\times 10^{9}\right)^{\mathrm{a}}$ & $0.6(0.3-0.9)$ & $0(0-0.1)$ \\
\hline \multicolumn{3}{|l|}{ Source of infection } \\
\hline Lung & 20 & 4 \\
\hline Blood & 9 & - \\
\hline Wound & 1 & - \\
\hline Line & 1 & 1 \\
\hline Culture negative & 3 & - \\
\hline Other & 1 & - \\
\hline \multicolumn{3}{|l|}{ Microbiological data } \\
\hline Gram negative bacteria & 9 & 2 \\
\hline Gram positive bacteria & 7 & 1 \\
\hline Polybacterial & 5 & - \\
\hline Fungi & 1 & 2 \\
\hline Fungi + bacterial & 9 & - \\
\hline Other & 4 & - \\
\hline
\end{tabular}

APACHE Acute physiology and chronic health evaluation, SOFA Sequential Organ Failure Assessment score

a Median and interquartile range
Plasma levels of $\operatorname{Trx}\left(101.3 \mathrm{ng} \mathrm{ml}^{-1}\right.$, IQR 68.7155.6) were significantly higher in patients with SIRS/ sepsis $(n=32)$ than healthy controls $\left(49.5 \mathrm{ng} \mathrm{ml}^{-1}\right.$, IQR 31.4-71.1, $n=17, P<0.001)$ or pre-oesophagectomy patients $\left(40.5 \mathrm{ng} \mathrm{ml}^{-1}\right.$, IQR 36.9-63.2, $n=7, P<0.01$; Fig. 1a). Plasma levels of MIF were also significantly higher in patients with SIRS/sepsis $\left(12.1 \mathrm{ng} \mathrm{ml}^{-1}\right.$, IQR 9.5-15.5, $n=35$ ) when compared with healthy controls (9.3 $\mathrm{ng} \mathrm{ml}^{-1}$, IQR 7.3-10.7, $n=20 ; P<0.01$; Fig. 1b). Plasma levels of neither Trx nor MIF correlated significantly with age $(r=0.18, P=0.29 ; r=-0.05$ and $P=0.77)$. Trx and MIF levels in patients with SIRS/ sepsis correlated significantly with each other $(r=0.63$, $P<0.0001$; Fig. 1c). The Pearson partial correlation coefficient of MIF with $\operatorname{Trx}(r=0.725, P<0.0001)$ was not significantly altered when age was a controlling variable $(r=0.725, P<0.0001)$.

The median APACHE II and SOFA scores are shown in Table 1. There was a positive correlation between plasma levels of Trx and APACHE II $(r=0.38$, $P<0.05$, Fig. 1d) but not SOFA scores $(r=-0.012$, $P=0.95)$ in the SIRS/sepsis group. By contrast, MIF levels in patients with SIRS/sepsis did not correlate with either APACHE II or SOFA (data not shown). There were no significant differences in Trx or MIF levels between patients surviving to hospital discharge or non-survivors (data not shown).

Plasma levels of IL-6, IL-8, IL-10 and PCT were significantly $(P<0.001)$ increased in SIRS/sepsis patients compared with control groups but did not correlate with either Trx or MIF levels (Table 2). None of the cytokines or PCT levels correlated with either APACHE II or SOFA scores (data not shown). However, when patients were grouped according to SOFA score bands, PCT levels in the 10-15 score group (5.6 $\mathrm{ng} \mathrm{ml}^{-1}$, IQR $0.95-8.2)$ were significantly greater than the $1-7$ score group $\left(0.58 \mathrm{ng} \mathrm{ml}^{-1}\right.$, IQR $\left.0.16-1.9, P=0.02\right)$ but not the 8-9 score group. Total leukocyte, neutrophil and monocyte cell counts were also measured in SIRS/sepsis patients (Table 1) but did not correlate with Trx levels $(r=-0.13,-0.15,-3$, respectively) or MIF levels $(r=-0.12,-0.2,-0.12$, respectively).

A small group of patients with neutropenic sepsis was recruited in order to assess the extent to which neutropenia during sepsis impacted on levels of Trx and MIF and for comparison cytokines and PCT. Demographic, clinical and microbiological information for patients with neutropenic sepsis are presented in Table 1. All patients had received recent chemotherapy to treat haematological cancers. There was no significant difference in IL-10 and IL-6 levels between neutropenic and non-neutropenic septic patients (Table 2). However, IL-8 and PCT levels were significantly $(P<0.01$ and $P<0.05$, respectively $)$ greater in neutropenics compared with the SIRS/sepsis group (Table 2). By contrast, in neutropenic patients levels of Trx (47.4 $\mathrm{ng} \mathrm{ml}^{-1}$, IQR 41.6-73.7) and MIF 
Fig. 1 Trx and MIF in SIRS/ sepsis. Concentrations of thioredoxin (a) and MIF (b) in plasma from healthy adult controls (closed circles), preoesophagectomy patients (preoes, crosses), patients with systemic inflammatory response syndrome/sepsis (SIRS/sepsis, inverted triangle). Data presented as scattergrams with median values indicated by horizontal lines; $* * P<0.01$, $* * * P<0.001$. Highly haemolysed blood samples were excluded from Trx analysis. Positive correlations between plasma levels of $\mathbf{c}$ thioredoxin and MIF $(r=0.63$,

$P<0.0001)$; and $\mathbf{d}$ thioredoxin and APACHE II scores $(r=0.38, P=0.05)$, in SIRS/ sepsis patients are also shown
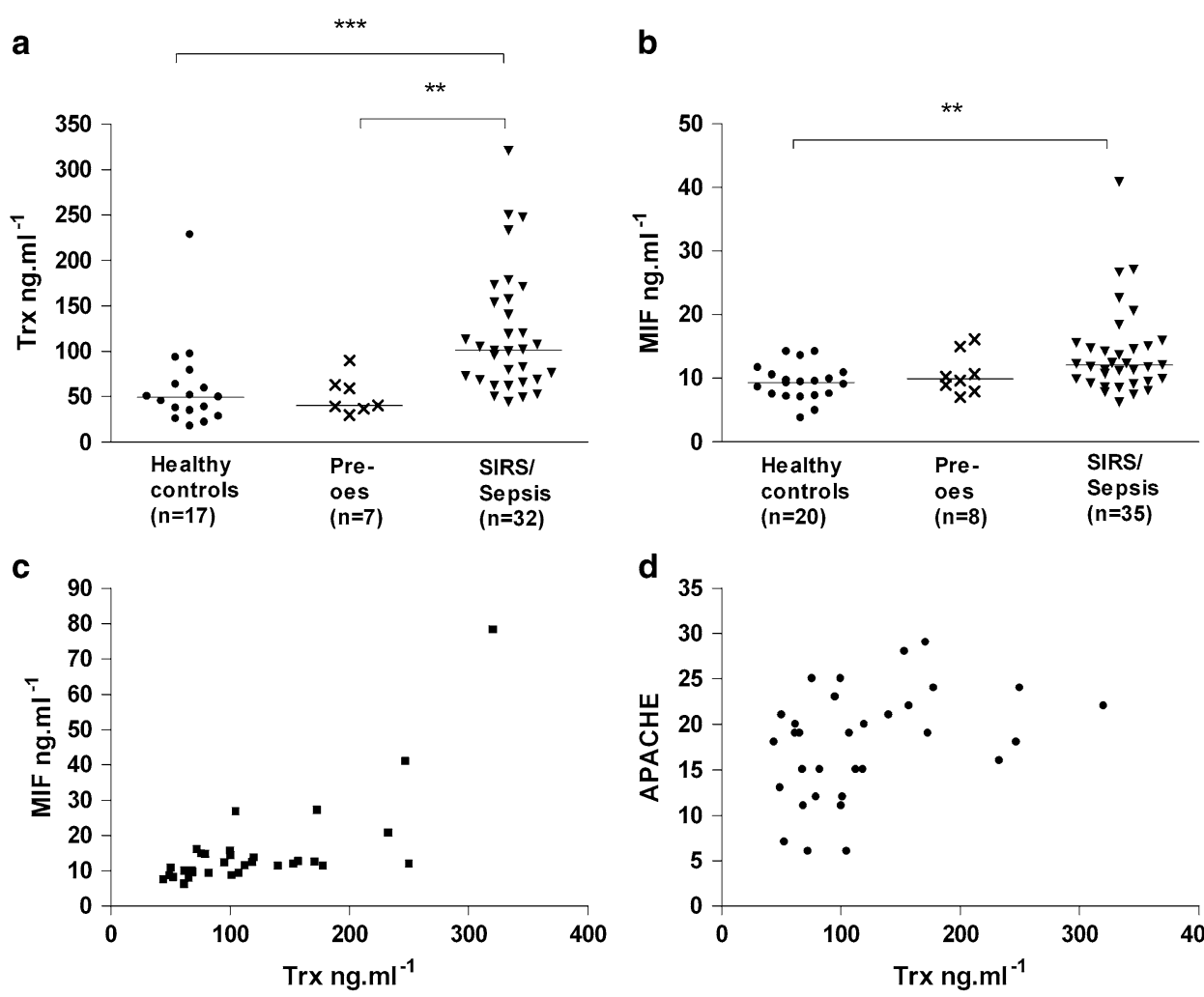

Table 2 Concentrations of IL-6, IL-8, IL-10 and PCT in plasma samples from healthy controls, pre-oesophagectomy patients and adults with SIRS/sepsis or neutropenic sepsis: median values (interquartile range)

\begin{tabular}{|c|c|c|c|c|}
\hline & IL-6 $\left(\mathrm{pg} \mathrm{ml}^{-1}\right)$ & IL-8 $\left(\mathrm{pg} \mathrm{ml}^{-1}\right)$ & IL-10 (pg ml $\left.{ }^{-1}\right)$ & PCT (ng ml ${ }^{-1}$ ) \\
\hline Heal & 0 & ) & 2) & 0.5 \\
\hline Pre-oesophagectomy $(n=8)$ & $0(0-4)$ & $10.8(8.9-13.9)$ & $0(0-1.2)$ & $0.5(0.05-0.05)$ \\
\hline SIRS/sepsis $(n=35)$ & $63.6(16.5-259.7)^{* *}$ & $36.4(27.6-67.7)^{* *}$ & $19.7(10.5-36.1)^{* *}$ & $1.77(0.69-5.92)^{* *}$ \\
\hline Neutropenics $(n=5)$ & $1193(183.4-1687)^{* *}, \mathrm{~ns}$ & $1169(217.3-1588) * *, \$ \$$ & $26.0(12.3-314.8)^{*}, \mathrm{~ns}$ & $8.64(4.4-63.5)^{* *, \$}$ \\
\hline MIF versus cytokine/PCT & $r=-0.043^{\mathrm{ns}}$ & $r=0.22^{\mathrm{ns}}$ & $r=0.07^{\mathrm{ns}}$ & $r=-0.14^{\mathrm{ns}}$ \\
\hline Trx versus cytokine/PCT ${ }^{\mathrm{a}}$ & $r=0.004^{\mathrm{ns}}$ & $r=0.27^{\mathrm{ns}}$ & $r=0.13^{\mathrm{ns}}$ & $r=-0.11^{\mathrm{ns}}$ \\
\hline
\end{tabular}

a Spearman non parametric analysis of correlations between cyto- $\$ p<0.05,{ }^{\$} p<0.01$, ${ }^{\mathrm{ns}}$ no significant difference, compared with kines or PCT and Trx or MIF

$* p<0.01, * * p<0.001$, compared with control groups SIRS/sepsis group

(8.9 ng ml${ }^{-1}$, IQR 5.6-11.9) were significantly lower $(P<0.01$ and $P<0.05$, respectively) when compared with levels in SIRS/sepsis patients (Trx, $101.3 \mathrm{ng} \mathrm{ml}^{-1}$, IQR 68.7-155.6; and MIF, $12.1 \mathrm{ng} \mathrm{ml}^{-1}$, IQR 9.5-15.5).

\section{Discussion}

Plasma levels of Trx and MIF were raised in patients with SIRS/sepsis but not neutropenic sepsis patients. Preoesophagectomy patients showed similar Trx and MIF plasma levels to healthy controls, suggesting hospitalization and/or intubation are unlikely to account for increased levels seen in SIRS/sepsis. Positive correlations between plasma Trx and MIF could suggest a linked role for these mediators in sepsis.

A doubling of plasma Trx in SIRS/sepsis is similar to the increase we have previously reported in patients with acute lung injury (ALI) [14] and others have shown in patients with severe sepsis [10]. By contrast, plasma Trx levels are lower in children with MSS compared with healthy controls [9]. Taken together these studies suggest that either extreme of Trx levels could be detrimental. We also report a 1.3-fold increase in plasma MIF in patients with SIRS/sepsis which contrasts previous reports of threefold increases, albeit with absolute MIF levels varying from lower than $[16,17]$, similar to $[2,18]$ or 
higher than [19] those reported in the present study. Differences in ELISA antibodies and assay protocols could account for differences in absolute MIF levels. Varying patient populations could explain variations in fold increases in MIF levels between ours and other studies. Thus, those recruited to our study were predominantly from a cardiothoracic ICU unit with secondary sepsis resulting, in the majority of cases, from lung infections. By contrast, other studies contained greater numbers of patients with abdominal complications [16, 17]. This may also account for the low PCT levels seen in the plasma from our patients with severe sepsis and septic shock. In addition, the survival rate of patients in our study was generally higher than in others.

Increases in plasma levels of IL-6, -8 and -10 in SIRS/ sepsis were similar to those in previous studies although lacked correlation, as shown by others, with disease severity, organ failure or survival [20]. Significantly higher levels of IL-8 in neutropenic patients compared to the SIRS/sepsis group also support the findings of others [21]. Raised levels of uric acid in LPS challenged neutropenic mice triggered cytokine release from tissue macrophages [22]. A similar mechanism might also explain raised IL-8 levels in neutropenic septic patients. With regard to links in SIRS/sepsis between Trx or MIF with cytokines there is no definite pattern; indeed, there are reports of positive, negative, or no, correlation in other studies [23, 24]. In view of these reports, lack of correlation between cytokines and Trx or MIF in the current study is perhaps unsurprising.

To our knowledge, only one previous study in patients with IBD has investigated the relationship between Trx and MIF and shown a positive correlation [11]. The correlation in the present study $(r=0.63, P<0.0001)$ suggests a robust link between variables. Moreover, it is comparable with the correlation we have identified between Trx and MIF in post-oesophagectomy patients ( $r=0.86, P=0.02 ; n=7$; Leaver et al., unpublished), further confirming a strong link between these variables.
Reduced sera and colonic tissue MIF was reported in Trxtransgenic mice and human monocytes treated with hrTrx released less MIF, indicative of anti-inflammatory effects of Trx on MIF [11]. Inter-dependent regulation of intracellular Trx and MIF impacting on functions such as apoptosis has also been reported [25, 26]. By contrast, the correlation between Trx and APACHE II was weak $(r=0.38)$ though statistically significant. We have previously failed to show correlation between Trx levels and APACHE II or SOFA scores [14]. In both current and previous studies the necessity of adapting the calculation of the scores to within $24 \mathrm{~h}$ of admission to the study might explain weaker correlation.

A concomitant decrease in Trx and MIF in patients with neutropenic sepsis suffering from malignancy further supports the idea that these mediators might be linked. Increased MIF and Trx levels might be predicted in neutropenic oncology patients given that raised plasma Trx and MIF levels are associated with cancer [27, 28]. Severely reduced leukocytes numbers could explain decreased Trx and MIF levels detected in neutropenic patients. However, no correlation was found between Trx and MIF with leukocyte cell counts. Alternatively, lower levels of oxidative stress in neutropenic patients [29] might explain the differences.

This seemingly tight connection between Trx and MIF levels in patients with sepsis represents an area for further research and possible target for therapeutic manipulation.

Acknowledgments S.K.L. and N.S.M. were supported by British Heart Foundation Clinical Research Training Fellowships. A.B.G. is supported by a Wellcome Trust University Award. We thank Jackie Donovan $(\mathrm{RBH})$ for her valuable assistance in measuring PCT and Dr. Richard Bogle and Dr. Simon Finney for their assistance with statistical analyses.

Open Access This article is distributed under the terms of the Creative Commons Attribution Noncommercial License which permits any noncommercial use, distribution, and reproduction in any medium, provided the original author(s) and source are credited.

\section{References}

1. Bernard GR, Ely EW, Wright TJ, Fraiz J, Stasek JE Jr, Russell JA, Mayers I, Rosenfeld BA, Morris PE, Yan SB, Helterbrand JD (2001) Safety and dose relationship of recombinant human activated protein $\mathrm{C}$ for coagulopathy in severe sepsis. Crit Care Med 29:2051-2059

2. Calandra T, Echtenacher B, Roy DL, Pugin J, Metz CN, Hultner L, Heumann D, Mannel D, Bucala R, Glauser MP (2000) Protection from septic shock by neutralization of macrophage migration inhibitory factor. Nat Med 6:164-170
3. Bozza M, Satoskar AR, Lin G, Lu B, Humbles AA, Gerard C, David JR (1999) Targeted disruption of migration inhibitory factor gene reveals its critical role in sepsis. J Exp Med 189:341-346

4. Calandra T (2003) Macrophage migration inhibitory factor and host innate immune responses to microbes. Scand J Infect Dis 35:573-576

5. Calandra T, Froidevaux C, Martin C, Roger T (2003) Macrophage migration inhibitory factor and host innate immune defenses against bacterial sepsis. J Infect Dis 187(Suppl 2):S385S390
6. Thiele M, Bernhagen J (2005) Link between macrophage migration inhibitory factor and cellular redox regulation. Antioxid Redox Signal 7:1234-1248

7. Kudrin A, Ray D (2008) Cunning factor: macrophage migration inhibitory factor as a redox-regulated target. Immunol Cell Biol 86:232-238

8. Burke-Gaffney A, Callister ME, Nakamura H (2005) Thioredoxin: friend or foe in human disease? Trends Pharmacol Sci 26:398-404 
9. Callister ME, Burke-Gaffney A, Quinlan GJ, Betts H, Nadel S, Evans TW (2007) Persistently low plasma thioredoxin is associated with meningococcal septic shock in children. Intensive Care Med 33:364-367

10. Hofer S, Rosenhagen C, Nakamura H, Yodoi J, Bopp C, Zimmermann JB, Goebel M, Schemmer P, Hoffmann K, Schulze-Osthoff K, Breitkreutz R, Weigand MA (2009) Thioredoxin in human and experimental sepsis. Crit Care Med 37:2155-2159

11. Tamaki H, Nakamura $H$, Nishio A, Nakase H, Ueno S, Uza N, Kido M, Inoue S, Mikami S, Asada M, Kiriya K, Kitamura H, Ohashi S, Fukui T, Kawasaki K, Matsuura M, Ishii Y, Okazaki K, Yodoi J, Chiba T (2006) Human thioredoxin-1 ameliorates experimental murine colitis in association with suppressed macrophage inhibitory factor production. Gastroenterology 131:1110-1121

12. Endo S, Aikawa N, Fujishima S, Sekine I, Kogawa K, Yamamoto Y, Kushimoto S, Yukioka H, Kato N, Totsuka K, Kikuchi K, Ikeda T, Ikeda K, Yamada H, Harada K, Satomura S (2008) Usefulness of procalcitonin serum level for the discrimination of severe sepsis from sepsis: a multicenter prospective study. J Infect Chemother 14:244-249

13. Bone RC, Sibbald WJ, Sprung CL (1992) The ACCP-SCCM consensus conference on sepsis and organ failure. Chest 101:1481-1483

14. Callister ME, Burke-Gaffney A, Quinlan GJ, Nicholson AG, Florio R, Nakamura H, Yodoi J, Evans TW (2006) Extracellular thioredoxin levels are increased in patients with acute lung injury. Thorax 61:521-527

15. Nakamura H, De Rosa S, Roederer M, Anderson MT, Dubs JG, Yodoi J, Holmgren A, Herzenberg LA (1996) Elevation of plasma thioredoxin levels in HIV-infected individuals. Int Immunol 8:603-611
16. Lehmann LE, Novender U, Schroeder S, Pietsch T, von Spiegel T, Putensen C, Hoeft A, Stuber F (2001) Plasma levels of macrophage migration inhibitory factor are elevated in patients with severe sepsis. Intensive Care Med 27:1412-1415

17. Bozza FA, Gomes RN, Japiassu AM, Soares M, Castro-Faria-Neto HC, Bozza PT, Bozza MT (2004) Macrophage migration inhibitory factor levels correlate with fatal outcome in sepsis. Shock 22:309-313

18. Gando S, Nishihira J, Kobayashi S, Morimoto Y, Nanzaki S, Kemmotsu O (2001) Macrophage migration inhibitory factor is a critical mediator of systemic inflammatory response syndrome. Intensive Care Med 27:1187-1193

19. Emonts M, Sweep FC, Grebenchtchikov N, Geurts-Moespot A, Knaup M, Chanson AL, Erard V, Renner P, Hermans PW, Hazelzet JA, Calandra T (2007) Association between high levels of blood macrophage migration inhibitory factor, inappropriate adrenal response, and early death in patients with severe sepsis. Clin Infect Dis 44:1321-1328

20. Livaditi O, Kotanidou A, Psarra A, Dimopoulou I, Sotiropoulou C, Augustatou K, Papasteriades C, Armaganidis A, Roussos C, Orfanos SE, Douzinas EE (2006) Neutrophil CD64 expression and serum IL-8: sensitive early markers of severity and outcome in sepsis. Cytokine 36:283290

21. Buyukberber N, Buyukberber S, Sevinc A, Camci C (2009) Cytokine concentrations are not predictive of bacteremia in febrile neutropenic patients. Med Oncol 26:55-61

22. Netea MG, Kullberg BJ, Blok WL, Netea RT, van der Meer JW (1997) The role of hyperuricemia in the increased cytokine production after lipopolysaccharide challenge in neutropenic mice. Blood 89:577-582
23. Ohashi S, Nishio A, Nakamura H, Kido M, Kiriya K, Asada M, Tamaki H, Fukui T, Kawasaki K, Watanabe N, Yodoi J, Okazaki K, Chiba T (2006) Clinical significance of serum thioredoxin 1 levels in patients with acute pancreatitis. Pancreas 32:264-270

24. Willeke P, Gaubitz M, Schotte H, Maaser C, Domschke W, Schluter B, Becker H (2007) Increased serum levels of macrophage migration inhibitory factor in patients with primary Sjogren's syndrome. Arthritis Res Ther 9:R43

25. Kondo N, Ishii Y, Son A, SakakuraNishiyama J, Kwon YW, Tanito M, Nishinaka Y, Matsuo Y, Nakayama T, Taniguchi M, Yodoi J (2004) Cysteinedependent immune regulation by TRX and MIF/GIF family proteins. Immunol Lett 92:143-147

26. Sato A, Hara T, Nakamura H, Kato N, Hoshino Y, Kondo N, Mishima M, Yodoi J (2006) Thioredoxin-1 suppresses systemic inflammatory responses against cigarette smoking. Antioxid Redox Signal 8:1891-1896

27. Bach JP, Deuster O, Balzer-Geldsetzer M, Meyer B, Dodel R, Bacher M (2009) The role of macrophage inhibitory factor in tumorigenesis and central nervous system tumors. Cancer 115:2031-2040

28. Marks PA (2006) Thioredoxin in cancer-role of histone deacetylase inhibitors. Semin Cancer Biol 16:436443

29. Neilly IJ, Copland M, Haj M, Adey G, Benjamin N, Bennett B (1995) Plasma nitrate concentrations in neutropenic and non-neutropenic patients with suspected septicaemia. Br J Haematol 89:199-202 